Bangladesh Journal of Neuroscience 2016; Vol. 32 (2): 63-67

\title{
Frequency of EEG Changes In Different Types of Clinically Diagnosed Epileptic Patients
}

\author{
DHALI SA ${ }^{1}$, BARMAN KK ${ }^{2}$, SHAHIDULLAH M² ${ }^{2}$ DEY SK ${ }^{2}$, ISLAM MR $^{3}$, ISLAM MF $^{4}$, ALAM MN $^{5}$
}

\begin{abstract}
:
Background: Diagnosis of epilepsy is based mainly on clinical history and examination. EEG constitutes the single most valuable laboratory test in the evaluation of patients with epilepsy. Objective: The objective of the present study was to find out the frequency of EEG abnormality among different types of clinically diagnosed epileptic patients. Methods: This cross-sectional study was carried out in the Department of Neurology, Bangabandhu Sheikh Mujib Medical University, Dhaka. A total of 152 epileptic patients attended in the Epilepsy Clinic, General OPD and EEG room of the Department of Neurology were enrolled for this study. Information on socio-demographic and seizure characteristics was obtained. The records from patients were obtained using the standard data collection form. Result: Out of 152 epileptic patients male were $62.5 \%$ and female were $37.5 \%$, mean age was $20.69 \pm 11.83$ years. Abnormal EEG was found in 81 (53.3\%) patients. Most of the patients 64 (79.0\%) had generalized epileptic discharge and 17 (21.0\%) had focal epileptic discharge. Out of 81 patients with abnormal EEG wave, 31 (38.3\%) patients had spike and wave, 26 (32.1\%) patients had sharp wave and 24 (29.6\%) patients had multiple types of EEG wave.Conclusion: The EEG is an important tool for diagnosing an epilepsy syndrome, knowledge of which aids in planning treatment and determining prognosis.
\end{abstract}

\section{Introduction:}

Epilepsy is a common chronic neurological disorder. More than half a century before the discovery of the human EEG, Hughlings Jackson offered a definition of epilepsy based on pathophysiology ${ }^{1}$. Though Gibbs and his colleagues ${ }^{2}$ discovered the pattern of epileptic discharges in 1935, the first description of an Epileptic crisis dates back to 3000 BC. Since the introduction, Electroencephalogram (EEG) has been used to diagnose and manage epilepsy. A seizure is any clinical event caused by abnormal electrical discharge in the brain whilst epilepsy is tendency to have recurrent seizures. ${ }^{3}$. In other words the term "Epilepsy" refers to recurrent and unprovoked seizures. About 50 million people worldwide have epilepsy, with almost $90 \%$ of these people being in developing countries ${ }^{4}$. There is a wide variation of incidence of epilepsy worldwide due to variation in classification system of epilepsy and methodology adopted in different studies ${ }^{5}$. The life time incidence of epilepsy varies from $2 \%$ to $5 \%$. With the incidence of 2-10 per thousand for South East Asian countries, it is estimated that there are 1.5-2 million people suffering from epilepsy in Bangladesh. Epilepsy is more likely to occur in young children or people over the age of 65 years, however it can occur at any time ${ }^{7}$. Broadly, epilepsies are classified as either generalized or partial with several subcategories in each class ${ }^{8}$. Most primary epilepsies are thought to have a genetic basis and their mode of inheritance is polygenic ${ }^{9}$. Its etiology and pathogenesis depends on multiple factors i.e. idiopathic, genetics, environmental, metabolic and various structural lesions in the brain. Epilepsy is mostly diagnosed

1. Medical Officer, Medicine OPD, Dhaka Medical College Hospital, Dhaka

2. Associate Professor, Dept. of Neurology, BSMMU

3. Professor, Dept. of Neurology, BSMMU

4. OSD, DGHS, Mohakhali, Dhaka

5. Junior Consultant, Medicine, UHC, Kashiani, Gopalganj 
clinically, but EEG remains central to the diagnosis of epilepsy ${ }^{10}$. Even with the tremendous advances in Neurodiagnostic procedure, the role of EEG is not abolished ${ }^{9}$.

\section{Methods:}

This cross-sectional descriptive study was carried out in Epilepsy Clinic, General OPD and EEG room in the Department of Neurology, Bangabandhu Sheikh Mujib Medical University (BSMMU), Dhaka over a period of two and half years from January 2014 to June 2016. A total of 152 clinically diagnosed epileptic patients attended in Epilepsy Clinic, General OPD and EEG were enrolled in this study. Epileptic patients having metabolic disturbances were excluded. In all cases single EEG was done following standard procedure by expert EEG technician using 10/20 channel EEG machine with photic stimulation, sleep deprivation and hyperventilation and EEG was done for at least 20-30 minutes. The demographic information, relevant history, examination findings and investigation reports of all the study subjects were recorded in the data collection sheet. Result was done by using Microsoft Excel.

\section{Results and Observation:}

In this study, mean age of the patients was $20.69 \pm 11.83$ years within the range of $1.5-75$ years. Male $(62.5 \%)$ were predominant than female (37.5\%). Male female ratio was 1.67:1. In this study, $102(67.1 \%)$ cases were generalized seizure and $50(32.9 \%)$ cases were focal seizure. Among generalized seizure patients most common clinical features were generalized convulsion $63.2 \%$, frothy mouth $61.8 \%$, loss of consciousness $59.9 \%$ and tongue bite $57.2 \%$ in case of generalized seizure and in focal seizure most common was abnormal movement $(20.4 \%)$. According to clinical diagnosis, most of the patients $(50.7 \%)$ had GTCS followed by $19(12.5 \%), 18(11.8 \%), 13(8.6 \%), 13(8.6 \%)$ and $12(7.9 \%)$ patients had focal seizure without impairment of consciousness, focal seizure with secondary generalization, absence seizure, focal seizure with impairment of consciousness and myoclonic seizure respectively. Abnormal EEG was found in $81(53.3 \%)$ patients, of them most of the patients $(65.3 \%)$ had generalized epileptic discharge and 25 (34.7\%) had focal epileptic discharge. Among focal epileptic discharge, 9 $(52.9 \%)$ patients had temporal focal seizure followed by $5(29.4 \%)$ and $3(17.7 \%)$ patients had frontal focal seizure and parietal focal seizure respectively. Among generalized seizures, 56 $(87.5 \%)$ patients had generalized epileptic discharge and $8(12.5 \%)$ patients had typical absence seizure. Out of 81 patients with abnormal EEG wave, $31(38.3 \%)$ patients had spike and wave, 26 (32.1\%) patients had sharp wave and 24 $(29.6 \%)$ patients had multiple types of EEG wave.

Table-I

Distribution of patients according to age $(n=152)$

\begin{tabular}{lcc}
\hline & Frequency & Percentage \\
\hline Age & & \\
Mean \pm SD & $20.69 \pm 11.83$ & \\
Range (min-max) & $1.5-75$ & \\
Gender & & \\
Male & 95 & 62.5 \\
Female & 57 & 37.5 \\
\hline
\end{tabular}

Table-II

Distribution of patients according to common presenting features $(n=152)$

\begin{tabular}{lcc}
\hline Presenting features & Frequency & Percentage \\
\hline Generalized seizure & 102 & 67.1 \\
Generalized convulsion & 96 & 63.2 \\
Frothy mouth & 94 & 61.8 \\
Loss of consciousness & 91 & 59.9 \\
Tongue bite & 87 & 57.2 \\
Post ictal confusion/ Headache & 77 & 50.7 \\
Urinary incontinence & 60 & 39.5 \\
Nocturnal attack & 34 & 22.4 \\
Focal seizure & 50 & 32.9 \\
Abnormal movement & 31 & 20.4 \\
Impairment of & 21 & 13.8 \\
consciousness and & & \\
abnormal mannerism & & \\
Convulsion starts on one & 11 & 7.2 \\
side then generalized & & 5.3 \\
Psychiatric symptoms & 8 & \\
\hline
\end{tabular}


Table-III

Distribution of patients according to clinical diagnosis $(n=152)$

\begin{tabular}{lcc}
\hline Clinical & Frequency & Percentage \\
\hline GTCS & 77 & 50.7 \\
Focal seizure without impairment of consciousness & 19 & 12.5 \\
Focal seizure with secondary generalization & 18 & 11.8 \\
Typical absence seizure & 13 & 8.6 \\
Focal seizure with impairment of consciousness & 13 & 8.6 \\
Myoclonic seizure & 12 & 7.9 \\
\hline
\end{tabular}

Table-IV

Distribution of patients according to clinical diagnosis and their EEG findings ( $n=152)$

\begin{tabular}{lccc}
\hline Clinical diagnosis & Total $(\mathrm{n}=152)$ & \multicolumn{2}{c}{ EEG } \\
\cline { 3 - 4 } & & Normal $(\mathrm{n}=71)$ & Abnormal $(\mathrm{n}=81)$ \\
\hline GTCS & 77 & $44.2 \%(34 / 77)$ & $55.8 \%(43 / 77)$ \\
Focal seizure without impairment of consciousness & 19 & $42.1 \%(8 / 19)$ & $57.9 \%(11 / 19)$ \\
Focal seizure with secondary generalization & 18 & $55.6 \%(10 / 18)$ & $44.4 \%(8 / 18)$ \\
Typical absence seizure & 13 & $38.5 \%(5 / 13)$ & $61.5 \%(8 / 13)$ \\
Focal seizure with impairment of consciousness & 13 & $53.8 \%(7 / 13)$ & $46.2 \%(6 / 13)$ \\
Myoclonic seizure & 12 & $58.3 \%(7 / 12)$ & $41.7 \%(5 / 12)$ \\
\hline Total & 152 & $46.7 \%(71 / 152)$ & $53.3(81 / 152)$ \\
\hline
\end{tabular}

Table V

Distribution of abnormal EEG findings in patients according to seizure type $(n=81)$

\begin{tabular}{lcc}
\hline Abnormal & Frequency & Percentage \\
\hline Focal epileptic discharge & 17 & 21.0 \\
Temporal & 9 & 52.9 \\
Frontal & 5 & 29.4 \\
Parietal & 3 & 17.7 \\
Generalized epileptic discharge & 64 & 79.0 \\
Generalized epileptic discharge & 56 & 87.5 \\
Typical absence seizure & 8 & 12.5 \\
\hline
\end{tabular}

Table-VI

Distribution of abnormal EEG wave $(n=81)$

\begin{tabular}{ccc}
\hline Abnormal activity & Frequency & Percentage \\
\hline Spike and wave & 31 & 38.3 \\
- Generalized epileptic discharge & 14 & 17.3 \\
- Focal epileptic discharge & 9 & 11.1 \\
- Typical absence seizure & 8 & 9.9 \\
Sharp and wave & 26 & 32.1 \\
- Generalized epileptic discharge & 23 & 28.4 \\
- Focal epileptic discharge & 3 & 3.7 \\
Multiple & 24 & 29.6 \\
- Generalized epileptic discharge & 19 & 23.5 \\
- Focal epileptic discharge & 5 & 6.2 \\
\hline
\end{tabular}




\section{Discussion:}

Diagnosis of epilepsy is based mainly on clinical history and examination. EEG constitutes the single most valuable laboratory test in the evaluation of patients with epilepsy. It is a safe, non-invasive procedure for evaluation of electrophysiological state of patients with epilepsy in the ictal or interictal period.

Marino et $\mathrm{al}^{6}$ showed that the incidence of epilepsy is highest at both extreme of ages, especially in neonatal period and after 6th decade. It varies among different age groups and forms a U-shape curve, which shows the lowest incidence for people between the age of 30 and 40 years. The highest incidence of epilepsy is seen in the first year of life as well as among the elderly ${ }^{11}$. In this study $84.2 \%$ patients were below or equal to 30 years of age. Chowdhury et al ${ }^{11}$ found $85.8 \%$ patients below 31 years and Owolabi et al ${ }^{12}$ found $74.5 \%$ of epilepsy were $<31$ years old. Most of the patients in this study were children and young adult.

This study showed that males $(62.5 \%)$ were more prone to epilepsy than females $(37.5 \%)$, this may be due to some of the risk factors, like trauma, are more common among males. In the study of Owolabi et al. ${ }^{12}$, male was $61.2 \%$ and female was $38.8 \%$. Similar result was seen in the study of Sidig et al. ${ }^{13}$ [Male was $54.1 \%$ and female was $45.9 \%$ ].

In this study, out of 152 patients most common clinical features were generalized convulsion $63.2 \%$, frothy mouth $61.8 \%$, loss of consciousness $59.9 \%$ and tongue bite $57.2 \%$ in case of generalized seizure and in focal seizure most common was abnormal movement $(20.4 \%)$. Almost similar result was found in the study of Sidig et $\mathrm{al}^{13}$.

In our study, among the clinically diagnosed epileptic patients most of them $(50.7 \%)$ had GTCS followed by 19 (12.5\%), 18 (11.8\%), 13 (8.6\%), 13 $(8.6 \%)$ and $12(7.9 \%)$ patients had focal seizure without impairment of consciousness, focal seizure with secondary generalization, absence seizure, focal seizure with impairment of consciousness and myoclonic seizure respectively in clinical diagnosis. Sidig et al. ${ }^{13}$ found that $86.4 \%$ had generalized epilepsy, while $13.6 \%$ had focal epilepsy clinically.
Most of our epileptic patients had generalized epilepsy, may be due to the fact that generalized epilepsy is dramatic in its presentation. So that affected people are interested to seek medical treatment, unlike focal seizures which may go unnoticed.

In this study abnormal EEG was found in $53.3 \%$ patients. Abnormal EEG was seen in $57.1 \%, 62.7 \%$ and $65.0 \%$ epileptic patients in the study of Owolabi et al. ${ }^{12}$, Chowdhury et al. ${ }^{12}$ and Sidig et al. ${ }^{13}$ respectively.

Most of the patients $(79.0 \%)$ had generalized epileptic discharge and $17(21.0 \%)$ had focal epileptic discharge in abnormal EEG. Sidig et al. ${ }^{13}$ reveled abnormal EEG in $64.8 \%$ cases, of them $86.4 \%$ had generalized discharges while $13.6 \%$ had focal discharge. Owolabi et al. ${ }^{12}$ found $51.5 \%$ generalized and $48.5 \%$ partial among abnormal EEG patients.

Among patients with focal seizure 9 (52.9\%) patients had temporal focal seizure followed by 5 $(29.4 \%)$ and $3(17.7 \%)$ patients had frontal focal seizure and parietal focal seizure respectively. Among the patients with Focal seizure, most common focus was temporal lobe. Temporal lobe was the most vulnerable part in focal seizure ${ }^{14}$.

Out of 81 patients with abnormal EEG wave, 31(38.3\%) patients had spike and wave, 26 (32.1\%) patients had sharp and wave and 24 (29.6\%) patients had multiple types of EEG wave. Among patients with epileptiform activity, generalized sharp and wave complexes and focal sharp and slow wave complexes were the most common finding ${ }^{13}$. In contrast to our findings Chowdhury et al. ${ }^{11}$ found $74 \%$ spike and wave, $11 \%$ sharp and wave $6 \%$ poly spikes and $2 \%$ slow waves, which probably accounts for the difference in age group of sample population.

\section{Conclusion:}

Based on the above study it can be concluded that diagnosis of epilepsy is based on clinical history and examination. EEG may constitute as one of the most valuable laboratory test in the evaluation of patients with epilepsy. The presence of an interictal spike/sharp wave helps to confirm a clinical diagnosis of epilepsy, aids in defining the 
epilepsy syndrome, provides information that assists in planning drug management and determining prognosis.

\section{References:}

1. Hughlings Jackson, J. On the anatomical, physiological and pathological investigation of epilepsies. West Riding Lunatic Asylum Medical Reports. 1873;3:315

1. 2 Gibbs FA, Davis H, Lennox WG. The electro encephalogram in epilepsy and in conditions of impaired consciousness. American Journal of EEG Technology. 1968 Jun 1;8(2):59-73.

2. Allen CMC, Lueck CJ, Dennis M. Neurologic disease. In: Colledge NR, Walker BR, Ralston $\mathrm{SH}$ (eds) Davidson's Principles and Practice of Medicine, $21^{\text {st }}$ edn. USA: Elsevier Limited. 2010.1172

3. Palmini A, Andermann F, Olivier A, Tampieri $D$, Robitaille $Y$, Andermann E, Wright G. Focal neuronal migration disorders and intractable partial epilepsy: a study of 30 patients. Annals of neurology. 1991 Dec 1;30(6):741-9.

4. Yacubian 2000. Yacubian EMT: Epilepsia: o conceito atual. In Epilepsia da Antiguidade ao Segundo Milênio. Edited by: Yacubian EMT. Lemos, São Paulo; 2000:82-8.

5. WHO 2015. Report on Epilepsy in South East Asia 'Some facts and figures in Epilepsy', Accessed on: 02-10-2015

6. Marino Jr RA, Cukiert A, Pinho E, Pinho E. Aspectos epidemiológicos da epilepsia em São Paulo. Arq Neuropsiquiatr. 1986;44(2):243-54.

7. King MA, Newton MR, Jackson GD, Fitt GJ, Mitchell LA, Silvapulle MJ, Berkovic SF. Epileptology of the first-seizure presentation: a clinical, electroencephalographic, and magnetic resonance imaging study of 300 consecutive patients. The Lancet. 1998;352(9133):1007-11.

8. Adams RD, Victor M, Rooper AH. (eds) Epilepsy and other seizure disorder, Principles of Neurology, $8^{\text {th }}$ edn, New York, USA: Mc Graw Hill Book Company. 2005. 271-95

9. Cascino GD. Use of routine and video electroencephalography. Neurologic clinics. 2001 May 1;19(2):271-87.

10. Forsgren L. and Hesdorffer D. Epidemiology and prognosis of epilepsy. In Shorvon S, Perucca E and Engel J, (eds), The Treatment of Epilepsy, $3^{\text {rd }}$ edn. London, UK: WileyBlackwell, 2009. 21-31.

11. Chowdhury RN, Hasan AH, Rahman KM, Mondol BA, Deb SR, Mohammad QD. Interictal EEG changes in patients with seizure disorder: experience in Bangladesh. SpringerPlus. 2013 Jan 29;2(1):1.

12. Owolabi LF, Shehu S, Owolabi SD, Umar M. Interictal electroencephalography in patients with epilepsy in northwestern Nigeria. Annals of Nigerian Medicine. 2013 Jul 1;7(2):48.

13. Sidig A, Hussein A, Yassien F, Hamad A, elAdil O, Saad M, Mubark B, Aldar MM. The pattern of clinical presentation of epilepsy among adolescence Sudanese epileptic patients. Journal of Neuroscience and Behavioral Health. 2011 Jan 31;3(1):1-7.

14. Aneesh P, Mohan M, Varma SC. The Study of Interictal Electro Encephalographic (EEG) patterns in different types of Seizures. International Journal of Scientific and Research Publications. 2013; 3(9), 1-2. 